\title{
Review of the carious lesions and traumatic dental injuries
}

\section{Introduction}

Children, who develop severe dental caries at an early age (12-36 months), as in nursing-bottle caries, present the dentist with one of the most perplexing situations in dentistry. Many dentists consider it hopeless to repair the damaged or even to explain how it could have happened at such an early age. Rampant caries has been described by Winter et al. ${ }^{1}$ as a lesion of acute onset involving many or all of the erupted teeth, rapidly destroying coronal tissues, often on surfaces normally immune to decay, and leading to early involvement of the dental pulp .In recent study, subjects with active, rampant dental caries were defined as those who had five or more now carious surfaces per year. ${ }^{2}$ Unfortunately, early rampant dental caries is very common today. The maxillary incisor teeth seem to be the most severely involved. Because dental caries in these cases begins prior to the eruption of posterior teeth, we would expect to see this type phenomenon. The remainder of the dentition is generally affected by caries in fairly constant way, if the disease is allowed to continue. The parents are also affected. Guilt feelings may develop in the concerned parent, or a feeling of helplessness may prevail, on the basis that the problem is considered of hereditary origin \& may exist throughout life. Finances can be critical factor in some families. Unfortunately, if the disease processes in not stopped, the child faces a complex and costly dental future. In the past, the most expedient treatment was to remove the involved teeth. We justified this treatment on the basis that permanent teeth would eventually replace the extracted teeth. The expected behavior of child less than two years of age also prevented an attempt at extensive treatment. However, now we recognize the importance of preserving the integrity of the primary dentition until the appropriate exfoliation time. Methods and materials have been developed to cope with these problems. It's well known that the consequences of the premature loss of the primary teeth can have a severe impact on the child's dental health. If these teeth are removed prior to the establishment of the primary occlusion, that is, before proper interdigitation occurs, serious problems may arise. Although anterior space loss occurs with less frequency and severity than posterior space loss, it should not be construed that it does not occur. The force, which inclines posterior teeth to the mesial during eruption, can have considerable impact on anterior space, if these teeth are lost prior to the establishment of the canine occlusion. Other conditions attributable to the early loss of the primary anterior teeth are described in the literature. Decreased efficiency of mastication, development of tongue habits, interference with the development of normal speech patterns, and the development of a malocclusion which may seriously affect the permanent dentition are examples of those conditions. The child's impaired appearance can affect its psychological development. A problem commonly faced in pediatric dental clinics is the restoration of primary maxillary incisors severely destroyed by trauma or caries. Most cases are observed in children with early childhood caries. Because of reduced coronal tooth structure, direct adhesive restorative procedures do not always give satisfactory results. ${ }^{3}$ The pediatric dentist who is presented with a patient with early childhood caries is faced with a difficult task of restoring the child's dentition to
Volume 6 Issue 6 - 2017

\author{
Ali Assiry \\ Department of Pediatric Dentistry, University of Najran, Saudi \\ Arabia \\ Correspondence: Ali Assiry, Department of Pediatric \\ Dentistry, College of Dentistry, University of Najran, Najran, \\ Saudi Arabia, Email ali 100mm@hotmail.com
}

Received: March 28, 2017| Published: April 07, 2017

good health. It is important to remember that before the restoration of crowns, endodontic treatment associated with the use of intra-canal retainer so always necessary. Different materials have been developed to restore teeth affected by nursing caries and many techniques have been suggested for the restoration of function. The use of adhesive techniques to bond dental fragments to the teeth has been proposed as an esthetic alternative for restoration of severely destroyed primary teeth. This technique was first used for restoration of fractured teeth using the own fractured tooth crown. In 1991, the term: "Biological restoration" was introduced to describe an alternative technique that uses adhesive capabilities of materials in combination with strategic placement of parts of extracted human permanent teeth to achieve better esthetics and more conservation of sound dental tissue.

Natural crowns have also been suggested as an option for restoring partially or completely lost dental crown. The technique of bonding tooth fragments was first proposed to repair permanent teeth with patient's own fractured crown fragment. However, it has also been performed to restore crowns severely destroyed by dental caries, using fragments from another patient. Moreover, extracted permanent teeth have been employed in removable and fixed prosthesis. Natural crowns and roots obtained from a tooth bank have been used for several clinical and laboratory procedures. They have been used for space maintenance in children, as a substitute for intra-coronal metal posts, and as biologic restoration for posterior and anterior primary teeth. Presently secure methods of sterilization and storage are available to ensure the safety of a tooth or tooth fragment from a tooth bank.

\section{Review of literature}

Snawder KD \& Gonzalez $\mathrm{We}^{4}$ have described a technique in their case report on management of severely diseased primary anterior teeth, where an immediate one sitting post and core were constructed in order to get retention for the polycarbonate crowns in anterior. The authors conclude that technique is simple and can be accomplished in one appointment. Simonsen $\mathrm{RJ}^{5}$ has described a case of traumatic fracture restoration in which the fractured incisal edges of two maxillary central incisors were bonded back in place. The 
acid etch technique, a Microfilled composite resin, and a V-shaped, notched bevel were used to restore a fractured central incisor. Dean JA et al. ${ }^{6}$ examined the relationships of tooth preparation and resin material types on repair of fractured anterior teeth by reattachment of fractured tooth fragments. A total of 44 extracted maxillary central incisors were tested. Statistical analysis revealed that no mechanical preparation of the enamel was as retentive as mechanical preparation of the enamel a 450 circumferential bevel $(\mathrm{P}<0.05)$. In addition as a chemically cured resin proved to be as retentive as chemically cured resin $(p<0.01)$. Also examined was the effect of the initial fracture angle on the retention of the attached fragment. Teeth fractured with an angle sloping cervically in a lingual-to-facial direction, when viewed proximally, were more retentive than other types of fractures $(p<0.05)$ when subjected to a lingually directed force from the labial aspect. Oluwole TO \& Dennis HL et al. ${ }^{7} 1986$, conducted a survey of 195 children with treated and untreated anterior tooth fractures. Their ages ranged from 11 to 21 years. The children were examined for the degree of fracture, Angle classification, amount of over jet, and DMFS. Results showed that both suffered injuries to their teeth more often than girls, the male-to-female ratio of the study population being 1.7: 1. A significant relationship was found among the frequency of traumatic injuries of permanent upper incisors incisal over jet, and the accident proneness of the children. Amir E \& Sarnat $\mathrm{H}^{8}$ reported a case of two immature maxillary central incisors with complicated fractures of the crowns, which were treated using the calcium hydroxide pulpotomy technique. Restoration of the crowns was accomplished by replacing the crown fragments using the acid etch technique. Follow-up at 36 months showed vital and functional pulp manifestation by dentinal bridge formation at the amputation site and completion of root formation. Dean JA \& Swartz MS ${ }^{9}$ examined the relationships of tooth preparation and resin material types in repair of fractured anterior teeth by reattachment of fractured tooth fragments. A total of 44 extracted maxillary central incisors were tested. Statistical analysis revealed that no mechanical preparation of the enamel was as retentive as a 450 circumferential bevel. In addition, a light-cure resin proved to be as retentive as a chemically cured resin. They also examined the effects of the initial fracture angle on retention of the attached fragment. Teeth fractured with an angle sloping cervically in a lingual-to-facial direction, when viewed proximally, were more retentive than other typed of fractures, when subjected to a lingually directed force from the labial aspect. De Angelis AJ \& Jungbluth $\mathrm{MA}^{10}$ described an example of anterior crown amputation and its subsequent reattachment by means of the acid-etch technique. Liew $\mathrm{P}^{11}$ has described a procedure in which the fractured portion of a traumatized tooth was re-etched to the crown using the acid-etch composite resin technique. The restoration had functioned successfully when reviewed six months later. The benefits of the procedure are discussed. Ehrmann $\mathrm{HE}^{12}$ has reported a case in the incisal edge of a maxillary anterior tooth on an 11-year-old boy was fractured resulting in a pulpal exposure. Root development of the tooth was complete. The tooth was treated using a partial pulpotomy and the fractured piece was reattached using an acid-etch composite. A radiograph taken 35 months post-operatively showed a dentinal bridge and healthy periapical tissues. Dorignac $\mathrm{G}$ et al. ${ }^{13}$ have reported the therapeutic principle and methods upon which the possibility of bonding the fragment is possible. This technique, which employs natural fragment of fractured anterior teeth, is a major advantage of restoring the integrity of the tooth with nearly invisible bonding. He concludes that the natural fragment used to insure the restoration "ad integrum" of the dental crown by simple bonding. The prognosis is excellent for a short term of several years. With expected improved materials in the future, these fragments may be kept for years.

Boratiera LN et al. ${ }^{14}$ have reported that reattachment techniques for tooth fragments present several advantages over restorations obtained with composite resin systems: better and long-lasting esthetics, improved function, a positive psychological response, and faster and less complicated procedures. Two clinical cases are presented to describe a treatment modality that restores, through the attachment of the dental fragment, the esthetics and function of anterior teeth in which fracture had invaded the biologic width. They have advocated that these procedures should be considered experimental surgery, not standard treatment. Yang ZP \& Chang $\mathrm{CS}^{15}$ have reported a successful case of homologous tooth transplantation of a maxillary second premolar obtained from a tooth bank, which was implanted into a fresh central incisor extracted site. A 3-year follow up radiograph indicated satisfactory apical healing and minimal replacement resorption. Clinically, the transplantation site was no evidence of periodontal disease or tooth mobility. Munksgaard EC et al. ${ }^{16}$ described a method by which the fracture strength of bonded, previously fractured incisors can be measured. This study was to develop a laboratory model suitable for testing the strength of the fractured incisors restored with bonding agents and resins, and to test the strength of teeth with a number of different dentin bonding systems. Using GLUMA and Scotch Bond, they have described a bonding technique to increase the fracture strength to $50 \%$ of original strength. Baratiera $\mathrm{LN}$ et al. ${ }^{17}$ have described a technique where esthetics and function were restored to fractured maxillary central incisors by reattaching the tooth fragment with the "sandwich" technique (glass-ionomer cement and composite resin). After 3 years, the tooth showed optimal fragment rehydration, presence of pulp vitality, absence of sensitivity, and a discrete color alteration in the line between the fragment and the dental remnant. Rueggberg $\mathrm{FA}^{18}$ reviewed the most recent developments to date and in intended to function both as information base of past experimental data as well as a source of guidance for further research. Santos JF \& Bianchi $J^{19}$ reported cases of severe coronal destruction, for which conventional dentistry must resort to complex techniques and combination of prosthetic materials. In addition, execution and placement of the restoration results on more destruction of sound dental tissue. An alternative technique has been presented that utilizes the adhesive capabilities of new materials in combination with strategic placement of parts of extracted human teeth to achieve better esthetics and more conservation of sound dental tissue. Burke $\mathrm{FJ}^{20}$ reported that with the introduction of the acid-etch technique with composite materials has revolutionized the restoration of fractured incisor teeth; it is possible that restoration of such teeth using the fractured fragment may produce a superior result. They have described technique, with possible advantages and disadvantages. Santos JF \& Bianchi $\mathrm{J}^{19}$ reported an alternative technique that utilizes the adhesive capabilities with strategic placement of parts of extracted human teeth to achieve better esthetics and more conservation of sound dental tissues. Typical cases of severely damaged crowns restored with composite resin, rather than metallic castings, are presented to illustrate the new technique. Diangelis AJ \& Jungbluth $\mathrm{M}^{21}$, have described and esthetic alternative technique for reattaching fractured tooth segments to bonded composite and full crowns, they have reviewed this technique and demonstrate its application. $\mathrm{Kanca}^{22}$ has presented a clinical report demonstrating reattachment of fractured incisor fragment. The fragment was replaced without the use of a filled composite resin, because the fracture had little splintering 
of the edges of the opposing pieces. An acid-etching procedure, wet bonding and surface disinfection prior to sealing of the wound site treated Frank pulpal exposure. At 1 year, the tooth was vital and had remaining totally asymptomatic. Zerman $\mathrm{N} \&$ Cavalleri $\mathrm{G}^{23}$, surveyed for prevalence of traumatic injuries to permanent incisors and their distribution according to type and some clinical factors and analyzed a total population of 2798 patients, aged 6-61 years, examined over a 5 year period in the Dental clinic of the University of Verone, Italy. This study noted the following points:

a. Preventive education programs should be instituted in the region, directed at parents and school teachers, to obtain cooperation attitude to treatment and food motivation in controls.

b. The necessity to unify the diagnostic and therapeutic protocol to provide reliable information in clinical investigations, to permit valid comparison with other studies and to improve the longterm prognosis of many cases.

Cordoso AC et al. ${ }^{24}$ have reported a case where Human natural teeth were used in manufacturing two complete prosthesis and two partial removable dentures in three patients. All four prosthesis continued to function satisfactorily. They have suggested that the practioner, by utilizing the patient's natural teeth in preference to artificial teeth, achieves an excellent means of solving the patient's esthetic problems. Baratieri LN et al. ${ }^{25}$ have reported a case of a maxillary central incisor fractured, invading the biologic width. The biologic width was surgically restored, and in the same session the fragment was reattached to the tooth remnant with a "new" dentinal adhesive system. Short-term results indicate the esthetics, function, and oral health has been maintained. Cavalleri \& Zerman $\mathrm{N}^{26}$, conducted a follow up study of crown fractured permanent incisors with incomplete root formation in a group of patients, aged 6-12 years, over a 5 year period in the Dental clinic of the University of Verona, Italy. Their study results confirm that crown fractures without pulp involvement in permanent incisors with incomplete root formation have a low percentage of pulpal complications, while $60 \%$ of the teeth with crown fractures with pulp involvement had pulp complications. Badami $\mathrm{AA}^{27}$, investigated the shear bond strength of sectioned bovine incisal edge fragments reattached using Gluma 2000 and scotch bond 2. The results showed that the mean force required fracturing incisal fragments rebonded using GLUMA 2000 was significantly greater than that required to fracture incisal fragments rebonded with Scotch bond 2 .

Andreasen FM et al. $^{28}$ in their clinical study involving three Scandinavian dental facilities, a series of 334 permanent incisors with fractures of the crown or crown and root was treated by reattachment of the fragment with a resin composite. Two centers employed acid etching of enamel alone for fragment bonding, while the third center used a combination of enamel etching and dentinal bonding. Although the final retention rate of fragment bonding was similar in the two groups, it took the dentinal bonding group almost three times as long to drop to $50 \%$ fragment retention. They have concluded that reattachment of the coronal fragment is a realistic alternative to placement of conventional resin-composite restorations. Abate RS et al. ${ }^{29}$, evaluated the bond strength of a compomers to dental enamel, dentin, and cementum. Their results showed that the use of acidetchant on enamel as a surface-conditioning step previous to priming with a primer and adhesive allowed a better bond between Dyract compomer and that substrate; acid-etching was not particularly needed an dentin and cementum. Dewald $\mathrm{JP}^{30}$ reviewed infection control concerns regarding the handling of teeth for research purposes that have prompted investigators to evaluate the effects of disinfections/ sterilization on extracted teeth. The objectives of his literature review were to assess the effect of disinfections or sterilization on teeth used for in vitro bonding studies and make recommendations on their use. Trushkowsky $\mathrm{RD}^{31}$ described the surgical and prosthetic treatment of a patient who sustained a fracture of the right lateral incisor during baseball practice. He has proposed that, the reattachment of a fractured clinical crown involving minimal invasion of the biologic width can be accomplished without conventional ostectomy and crown lengthening so that satisfactory esthetics can be achieved. Adhesive techniques sometimes in conjunction with additional mechanical retention, such as a post, can be to reattach the fractured segment. An esthetic results be obtained with a minimal number of procedural cost to the patient. Farik B et al. ${ }^{32}$ described the effect on fracture strength of fragments dried and rewetted for various periods of time prior to bonding. Statistical analysis revealed that the fracture strength of the fragment -bonded teeth was unaffected by air storage of the fragment for up to $1 \mathrm{hr}$ prior to bonding, after which additional drying resulted in decreased fracture strength. Fragments dried for $24 \mathrm{hrs}$ in air and rewetted by immersion in water for at least 1 day were fragment bonded without loss of fracture strength. Thus placing emphasis on proper hydration of tooth fragment prior to reattachment. Murchison DF et al. ${ }^{33}$ reviewed the evolution of the incisal edge reattachment procedure. A review is provided of present in vivo studies detailing long-term success rates in the clinical application of this procedure. He has also presented a case reports that described of patients presenting with traumatized teeth in which there attachment procedure was performed ans results satisfactorily obtained. Finally, he has commended technique for diagnosis and treatment is offered to improve success in this procedure, which may benefit a significant segment of the pediatric and adolescent populations. Worthington $\mathrm{RB}$ et al. ${ }^{34}$ evaluated the effect of preparation utilization and design, and addition of resin composite to the bonding interface, on the fracture resistance of reattached incisal fragments. They observed and concluded that the compared to the simple, expedient regimen of using dentin bonding agent alone, non conservative tooth modification and addition of resin composite to the bonding interface did not increase resistance to fracture and thus provided no retention advantage. Wanderley MT et al. ${ }^{3}$ have described a simple and effective and represents a promising alternative for prosthodontic restoration in clinical pediatric dentistry. The technique can be used to restore severely carious pediatric dentistry. The use of $\mathrm{Ni}-\mathrm{Cr}$ cast posts with macro retentive elements and indirect resin crowns resulted in clinical success, reestablishing function and restoring esthetics. Romito AC et al. ${ }^{35}$ reported a "biologic" restoration technique in which natural roots and crowns and adhesive materials were used to restore primary anterior teeth that had lost their crown. They have also reported a case also and described their entire technique methodically.

Lui $\mathrm{JL}^{36}$ reported a case of reattachment of fractured root fragment and resin-composite reinforcement in a compromised endodontically treated root. He has other clinical applications of the composite reinforcement technique for the attachment of a fracture root fragment in a compromised root-filled tooth. Chu FC et al. ${ }^{37}$ in their report, a systematic clinical approach through evaluation of periodontal, endodontic, coronal and occlusal aspects is presented to help dentists analyze the factors affecting selection of techniques and materials. In addition, use of adhesive materials for tooth fragment reattachment is illustrated. Modifications of the reattachment process, including 
placement of veneer and radicular post, are also discussed. Reis A et al. ${ }^{38}$ in their clinical relevance of re-attachment of coronal fragments to the remaining tooth, using an over contour or an internal groove technique as well as a composite build-up, have stated that it can provide high fracture strength to restored teeth. Barcelos \& Souza IP ${ }^{39}$, have evaluated the clinical conducts recommended in Brazilian schools of Dentistry for oral rehabilitation in Pediatric Dentistry. Questionnaires were sent to the coordinators of the pediatric dentistry area of 84 schools of dentistry listed in the Federal Council of Dentistry. The questions broached resources for rehabilitation in cases of multiple and unitary losses and major crown destruction, advantages, flaws and the child's satisfaction using them. Thirty-eight questionnaires returned representing 11 Brazilian states. It was found that in deciduous teeth, the removable prosthesis was the most recommended apparatus in the case of a unitary $(65.0 \%)$ and multiple anterior loss $(100 \%)$, and multiple posterior loss $(64.7 \%)$ and also as a temporary substitute for permanent teeth .To unitary substitution of deciduous teeth, the loopband apparatus was the most used $(76.0 \%)$. The removable prosthesis was indicated as the resources that most used repairing $(77.7 \%)$ either due to the acrylic breaking $(84.6 \%)$ or the clamps $(71.6 \%)$ or that it is easy to lose $(84.6 \%)$. Regarding fixed apparatus, the main reasons for their repair were a crack in the weld region $(55.3 \%)$ and defective cementing $(57.6 \%)$. Based on the teacher's observation, $(15.2 \%)$ said that all the types of apparatus satisfy than child, although they prefer the removable types of apparatus $(36.8 \%)$. The materials recommended for restoring much damaged teeth were resin (94.7\%), bonding of tooth fragments $(63.2 \%)$. The main reason for why it was chosen was that it is practical to handle and long lasting restoration allied to appearance. It is concluded that the removable prosthesis and composite resin restoration are the resources most used in oral rehabilitation in Pediatric Dentistry by Brazilian universities, which seek to use in when attending the rehabilitation patient's necessities and when teaching their students.

Olsburgh $\mathrm{S}$ et al. ${ }^{40}$, in their review paper discusses the different types of crown fracture, from the uncomplicated to complicated, including crown-root fractures. It focuses on two different aspects: the pulp, with an attempt to correlate epidemiological, experimental, histopathological and clinical studies, so that the clinician can better understand the underlying processes accounting for success or failure to maintain pulp vitality. Also, they have considered the restoration: knowledge about bonding to dentin and new material as it is evolving extremely quickly making it difficult for the clinician to keep up with the developments. If handled properly, prognosis of the pulp, after traumatic crown fracture, is good. Prognosis of the restoration has also improved considerably over the last few years, and it appears that this trend will continue in the future. Rappelli $\mathrm{G}$ et al. ${ }^{41}$ described the clinical procedures for the immediate fragment reattachment by accurate bonding procedures. The immediate fragment reattachment is a very conservative treatment; it allows the restoration of the original dental anatomy, thus rehabilitating function and esthetics in a short time, by preserving dental tissues. Farik B et al..$^{42}$, measured the strength of restored fractured incisors, bonded with one of a number of different single-bottle dentin adhesives used with and without an unfilled resin. The results showed that of all tested adhesives except one could be for fragment bonding with an unfilled resin to make a strong bond between the fragment and the tooth. Barcelos et al. ${ }^{43}$ reported a case of oral rehabilitation in a 4-year-old girl, in which the posterior teeth were restored using biological restorations. The tooth fragments were selected from a bank of tooth tissues and bonded with dual - cure composite cement to prepared teeth. The results were satisfactory regarding retention, aesthetics and mastication, but disadvantages included long clinical appointments, laborious technique and possible fracture or degradation, between the margins of the fragments and the tooth surface.

Bussadori SK et al. ${ }^{44}$ described restorative treatment of esthetic veneer (facet) of human dental enamel in three-year old child after trauma that caused concussion and accentuated color alteration. Clinical results showed an efficient esthetical resolution, revealing it to be a good alternative for treatment of traumatized anterior decidous teeth. Mandroli PS ${ }^{45}$ reported a case of three and half year old child treated for rampant caries and rehabilitated. Here a natural crown from a tooth bank was employed to restore the lost coronal structure. The technique description of this method and merits has described. He concludes that this type of biologic restoration is a promising alternative to prosthodontic restoration for primary teeth severely destroyed due to caries. Also, the technique eliminates high costs associated with other restorative techniques for deciduous anterior teeth, because stored extracted over-over retained deciduous teeth were used for the procedure. Howell ${ }^{46}$ has presented a technique for temporarily repairing the complete fracture of an anterior tooth in which he has described a simple, esthetic and quick method for restoring a maxillary anterior tooth that has experienced complete horizontal fracture employing immediate customized composite post and core. Spinas $\mathrm{E}^{47}$ presented two case illustrations states that of all the kinds of traumatic dental injury, luxation injuries associated with crown-root fractures deserves special attention due to the particular need for complex multidisciplinary treatment. Clinical experience has demonstrated the need for repositioning of luxated teeth and treatment of crown-root fractures by orthodontic or surgical extrusion and completed with periodontal plastic surgery (gingivoplasty). In many cases outcome is good conservation and excellent esthetic results. This approach cannot however, always be recommended, for example because of the age of the patient. For this reason, a different protocol is proposed that involves, in addition to orthodontic repositioning of the luxated teeth, (as is required to return teeth to the physiologic position), the extrusion, restoration and subsequent re-intrusion to the natural position (without the need for further surgery) of those teeth involved with associated crown-root fractures. Chauhan $\mathrm{M}^{48}$ in his article describes the rational and method of using glass fibers reinforced with resin composite as an external framework to reuse a patient's own anterior tooth as a pontic, after extraction .As a clinical relevance he states that a natural tooth pontic fixed partial denture using fiber-reinforced composite offers a conservative, cost-effective, noninvasive, esthetic, functional, and durable solution for replacing a single anterior tooth. Mortada A \& King $\mathrm{NM}^{49}$ have stated that the restoration of severely carious primary anterior teeth is a challenge to the pediatric dentist. The introduction of new materials and technologies makes re-evaluation of existing treatment philosophies necessary. A technique involving the placement of an omega shaped stainless steel wire extension into the entrance of the root canal prior to restoring the crown with a compomer material is described. 96 restorations were placed in 25 children. After 18 months $81.2 \%$ of the 96 restorations, which were available for evaluation, 60(79.9\%) were intact. The technique for restoring primary anterior teeth was simple, quick and effective.

\section{Acknowledgments}

None. 


\section{Conflicts of interest}

The authors declare there is no conflict of interest.

\section{References}

1. Winter GB, Hamilton Mc, James PMC. Role of the comforter as an etiological factor in rampant caries of the deciduous dentition. Arch Dis Child. 1966;417:207-212.

2. Tinanoff N, Knock B, Camosci DA, et al. Microbiologic effects of SnF2 and $\mathrm{NaF}$ mouthrinses in subjects with high caries activity: results after one year. J Dent Res. 1983;62(8):907-911.

3. Wanderley MT, Ferreira SLM, Rodrigues C, et al. Primary anterior restoration using posts with macro retentive elements. Quintessence Int. 1999;30(6):432-436.

4. Snawder KD, Gonzalez WE. Management of severely diseased primary anterior teeth. ASDC J Dent Child. 1975;42(3):181-185.

5. Simonsen RJ. Restoration of a fractured central incisor using original tooth fragments. JADA. 105(4):646-648.

6. Dean JA, Avery DR, Swartz ML. Attachment of anterior tooth fragments. Pediatr Dent. 1986;8(3):139-143.

7. Oluwole TO, Dennis HL. Clinical and epidemiological survey of adolescence with crown fractures of permanent anterior teeth. Pediatr Dent. 1986;8(3):221-225.

8. Amir E, Bar Gil B, Sarnat H. Restoration of fractured immature maxillary central incisors using the crown fragments. Pediatr Dent. 1986;8(4):285288.

9. Dean JA, Swartz MS. Attachment of anterior tooth fragments. Pediatr Dent. 1986;8(3):139-143.

10. De Angelis AAJ, Jungbluth MA. Restoration of an amputated crown by the acid-etch technique. Quintessence Int. 1987;18(12):829-832.

11. Liew PW. Re-attachment of original tooth fragment to a fractured crown. Case report. Aus Dent J. 1988;33(1):47-50.

12. Ehrmann HE. Restoration of a fractured incisor with exposed pulp using original tooth fragment: report of case. JADA. 1989;118(2):183-185.

13. Dorignac G, Nancy J, Griffins D. Bonding of natural fragments to fractured anterior teeth. J Pedodont. 1990;14:132-135.

14. Boratiera LN, Monteiro S, Andrada M. Tooth fracture reattachment: case reports. Quintessence Int. 1990;21(4):261-270.

15. Yang ZP, Chang CS. A three Year follow-up of a Homotransplanted tooth from a tooth bank. J Endodon. 1990;16(1):34-37.

16. Munksgaard EC, Hojtved L, Jorgensen E, et al. Enamel-dentin fractures bonded with various bonding agents. Endod Dent Traumatol. 1991;7(2):73-77.

17. Baratiera LN, Monteiro S, Andrada M. The "Sandwich" technique as a base for reattachment of dental fragments. Quintessence Int. 1991;22(2):81-85.

18. Rueggberg FA. Substrate for adhesion testing to tooth structure-Review of the literature. Dent Mater. 1991;7(1):5-10.

19. Santos JFF, Bianchi J. Restoration of severely damaged teeth with resin bonding systems: case reports. Quintessence Int. 1991;22(8):611-615.

20. Bruke FJ. Reattachment of a fractured central incisors tooth fragment. $\mathrm{Br}$ Dent J. 1991;170:223-225.

21. Diangelis AJ, Jungbluth M. Reattaching fractured tooth segment: an esthetic alternative. JADA. 1992;123(8):58-63.
22. Kanca. Replacement of a fractured incisor fragment over pulpal exposure: A case report. Quintessence Int. 1993;24(2):81-84.

23. Zerman N, Cavalleri G. Traumatic injuries to permanent incisors. Endod Dent Traumatol. 1993;9(2):61-64.

24. Cordoso AC, Arcari GM, Zendron MV, et al. The use of natural teeth to make removable partial prosthesis and complete prosthesis. Quintessence Int. 1994;25(4):239-243.

25. Baratieri LN, Monteiro S, Albuquerque FM, et al. Reattachment of a tooth fragment with a "new" adhesive system: A case report. Quintessence Int. 1994;25(2):91-96.

26. Cavalleri G, Zerman N. Traumatic crown fractures in permanent incisors with immature roots: a follow-up study. Endod Dent Traumatol. 1995;11(6):294-296.

27. Badami AA, Dunne SM, Scheer B. An in vitro investigation into the shear bond strengths of two dentine bonding agents used in the reattachment of incisal edge fragments. Endod Dent Traumatol. 1995;11(3):129-135.

28. Andreasen FM, Noren JG, Andreason JO, et al. Long-term survival of fragment bonding in the treatment of fractures crowns: A multicenter clinical study. Quintessence Int. 1995;26(10):669-681.

29. Abate PF, Bertacchini SM, Polack MA, et al. Adhesion of compomer to dental structures. Quintessence Int. 1997;28(8):509-512.

30. Dewald JP. The use of extracted teeth for in vitro bonding studies; a review of infection control considerations. Dent Mater. 1997;13(2):74-81.

31. Trushkowsky RD. Esthetic, biologic and restorative consideration in coronal segment reattachment for a fractured tooth: A clinical report. $J$ Prosthet Dent. 1998;79(2):115-119.

32. Farik B, Munksgaard EC, Andreasen JO, et al. Drying and rewetting anterior crown fragments prior to bonding. Endod Dent Traumatol. 1999;15(3):113-116.

33. Murchison DF, Burke FJT, Worthington RB. Incisal edge reattachment: indications for use and clinical technique. Br Dent J. 1999;186:614-619.

34. Worthington RB, Murchison DF, Vandewelle KS. Incisal edge reattachment: The effect of preparation and design. Quintessence Int. 1999;30(9):637-643.

35. Romito AC, Wanderley MT, Oliveira MDM, et al. Biologic restoration of primary anterior teeth. Quintessence Int. 2000;31(6):405-411.

36. Lui JL. A case report of reattachment of fractured root fragment and resincomposite reinforcement in a compromised endodontically treated root. Dent Traumatol. 2001;17(5):227-230.

37. Chu FCS, Yim TM, Wei S. The clinical considerations for reattachment of tooth fragments. Quintessence Int. 2000;31(6):385-391.

38. Reis A, Francci C, Loguercio AD, et al. Re-Attachment of anterior fractured teeth: Fracture strength using different techniques. Oper Dent. 2001;26(3):287-294.

39. Barcelos, Souza IR. Oral rehabilitation in pediatric dentistry-A profile of Brazilian universities. J Dent Res. 2001;80:963.

40. Olsburgh S, Jacoby, Krejci I. Crown fractures in the permanent dentition: Pulpal and restorative considerations. Dent Traumatol. 2002;18(3):103115.

41. Rappelli G, Massaccesi C, Putignano A. Clinical procedures for the immediate reattachment of a tooth fragment. Dent Traumatol. 2002;18(3):281-284.

42. Farik B, Munksgaard EC, Andreasen JO, et al. Fractured teeth bonded with dentin with dentin adhesives with and without unfilled resin. Dent Traumatol. 2002;18(2):66-69. 
43. Barcelos R, Neves AA, Primo L, et al. Biologic restoration as an alternative treatment for primary posterior teeth. $J$ Clin Pediatr Dent. 2003;27:305-310.

44. Bussadori SK, Rego MA, Pereira RJ, et al. Human enamel veneer restoration in a decidous tooth: Clinical case. $J$ Clin Pediatr Dent. 2003;27(2):111-115.

45. Mandroli PS. Biologic restoration of primary anterior teeth: A case report. J Indian Soc Pedo Prev Dent. 2003;21:95-97.

46. Howell BE. Technique for temporarily repairing the complete fracture of an anterior tooth. JADA. 2003;134(10):1359-1360.
47. Spinas E. A biological conservative approach to complex traumatic dentoalveolar lesions. J Clin Pediatr Dent. 2003;28(1):1-10.

48. Chauhan M. Natural tooth pontic fixed partial denture using resin composite-reinforced glass fibers. Quintessence Int. 2004;35(7):549-553.

49. Mortada A, King NM. A simplified technique for the restoration of severely mutilated primary anterior teeth. J Clin Pediatr Dent. 2004;28(3):187192. 